\title{
COMBUSTION, PERFORMANCE AND EXHAUST EMISSIONS OF THE DIESEL ENGINE OPERATING ON JET FUEL
}

\author{
Gvidonas Labeckas, Stasys Slavinskas \\ Transport and Power Machinery Department \\ Engineering Faculty, Aleksandras Stulginskis University (ASU) \\ Student Street 11, P.O. Box LT-53361, Kaunas Academy, Lithuania \\ tel./fax: +370 37752311 \\ e-mail:gvidonas.labeckas@asu.lt,stasys.slavinskas@asu.lt \\ Valentina Vilutienè \\ Engineering Management Department \\ The General Jonas Zemaitis Military Academy of Lithuania \\ Silo Street 5a., P.O.BOX LT-10322, Vilnius, Lithuania \\ tel./fax: +370 37 2126923; fax: +370 372127318 \\ e-mail:valentina.vilutiene@mil.lt
}

\begin{abstract}
The article focuses on bench testing results of a four-stroke, four-cylinder, direct-injection, naturally aspirated diesel engine operating on the normal $95 \mathrm{vol} \%$ (class C) diesel fuel $+5 \mathrm{vol} \% \mathrm{RME}(\mathrm{DF}), \mathrm{F}-34$ jet fuel (JF) and jet fuel F-34 treated with the cetane improver $(J F+0.12 \mathrm{vol} \%)$. The purpose of the research is to investigate the availability to use of military F-34 jet fuel for land-based direct injection diesel engine powering and examine the effect of F-34 fuel and F-34 fuel treated with 0.12 vol\% 2-ethylhexyl nitrate on the autoignition delay, combustion, engine performance, emissions and smoke opacity of the exhausts.

The peak in-cylinder gas pressure generated from JF and JF+0.12vol\% is lower by $4.3 \%$ and $2.8 \%$ at $1400 \mathrm{~min}^{-1}$ speed, and $2.5 \%$ and $5.7 \%$ at $2200 \mathrm{~min}^{-1}$ speed compared to that $86.6 \mathrm{MPa}$ and $82.5 \mathrm{MPa}$ of the normal diesel. At rated $2200 \mathrm{~min}^{-1}$ speed, the use of treated jet fuel leads to smoother engine performance under all loads and the maximum cylinder pressure gradient lowers by $9.4 \%$ as against that 15.9 bar/deg of base diesel. The minimum brake specific fuel consumption (bsfc) for F-34 and treated F-34 fuels decreases by $4.8 \%$ and 3.5\% at $1400 \mathrm{~min}^{-1}$ speed and increases by $2.7 \%$ and $3.7 \%$ at $2200 \mathrm{~min}^{-1}$ speed compared to $249.5 \mathrm{~g} / \mathrm{kWh}$ and $251.8 \mathrm{~g} / \mathrm{kWh}$ values of base diesel.

Maximum NO emissions produced from fuels $\mathrm{JF}$ and $\mathrm{JF}+0.12 \mathrm{vol} \%$ decrease by $11.5 \%$ and $7.0 \%$ at $1400 \mathrm{~min}^{-1}$, and $17.1 \%$ and $17.3 \%$ at $2200 \mathrm{~min}^{-1}$ speed compared to $1705 \mathrm{ppm}$ and $1389 \mathrm{ppm}$ emanating from the normal diesel. Maximum CO emissions produced from jet fuel $\mathrm{JF}$ and $\mathrm{JF}+0.12 \mathrm{vol} \%$ decrease by $39.3 \%$ and $16.8 \%$ compared to that $4988 \mathrm{ppm}$ produced from base diesel running at $1400 \mathrm{~min}^{-1}$ speed. At $2200 \mathrm{~min}^{-1}$ speed, the ecological effect of using fuel F-34 fuel decreases and the CO sustains over the whole load range at the same level and increases by $2.5 \%$ and $3.0 \%$ with regard to the normal diesel operating under high load. The HC emission also is lower by 78.3\% and 58.8\% for low and high loads compared to 230 ppm and 1820 ppm of the normal diesel running at $1400 \mathrm{~min}^{-1}$ speed. The smoke opacity generated from fuels JF and JF+0.12vol\% sustains at lower levels over the all load range with the maximum values decreased by $14.6 \%$ and $8.1 \%$ with regard to $94.9 \%$ of the normal diesel operating at $1400 \mathrm{~min}^{-1}$ speed. The test results show that military F-34 fuel is a cleaner-burning replacement of diesel fuel and suggests fuel economy with reduced all harmful species, including $\mathrm{NO}, \mathrm{NO}_{2}, \mathrm{NO}_{x}, \mathrm{CO}, \mathrm{HC}$, and smoke opacity of the exhausts.
\end{abstract}

Keywords: diesel engine, jet fuel, autoignition, combustion, performance, emissions, smoke

\section{Introduction}

Fuel is a commodity that is essential to NATO defence planning and is also necessary for sustaining social and economic life. The MC-473 Directive provides guidance to NATO and national authorities on the policies, principles, and characteristics of the NATO Petroleum Supply Chain. The aim of the original Single Fuel Concept (SFC) was conceived after the Second World War in order to simplify the logistic supply chain for petroleum products in the NATO nations and 
to achieve maximum equipment interoperability through the using of a single fuel, namely F-34, on the battlefield for land-based military aircrafts, vehicles, and equipment. Since its inception as a concept in 1986, the adoption of the SFC has been supported by a number of studies and trials in Member and Partner nations. At its autumn meeting in 2004, the NATO Pipeline Committee (NPC) adopted the SFP as the NATO Single Fuel Policy [1].

The logic behind such a decision comes not only from the gain of big logistical prizes in war time, but also from the more pragmatic fact of being able both to simplify and to make better use of the NATO extensive and expensive pipeline system in times of peace. The single fuel selected has been the F-34 (JP-8) military jet kerosene, which is based upon the civil jet fuel F-35 (Jet A-1), which is widely available throughout the European arena, with the inclusion of military additive possessing anti-icing and lubricating properties [2].

Prior to the decision, member nations of NATO have undertaken studies in order to identify problems that could arise in practice by the use of the kerosene based fuel in diesel engine vehicles (tanks, transporters etc.). One of the problems can be linked with the reduced lubricity of a lighter kerosene based jet fuel that may affect reliability and durability of diesel engine. The development of biomass derived substitutes for diesel fuel is a possible attractive outlet, as it could help to improve the quality. The bench tests conducted with a single cylinder, stationary direct injection Petter engine, model AV1-LAB showed that the substitution of F-34, which is comparable with commercial aviation fuel JP-8, with sunflower oil and/or olive oil at proportions from $10 \%$ to $50 \%$ results in slightly increasing the volumetric fuel consumption, a strong tendency to decreasing PM emissions and both positive and negative changes of nitrogen oxide emissions depending on the percentage of biofuel added in the JP-8 and engine load [2].

An experimental study carried out in an optically accessible single-cylinder heavy-duty diesel engine equipped with a high-pressure common-rail injection system showed that spray tip penetration of JP-8 was shorter than that of diesel fuel by approximately $16 \%$ when the injection pressure was $30 \mathrm{MPa}$ and $10 \%$ with increased injection pressure at $140 \mathrm{MPa}$. The decreased spray tip penetration was accompanied by $15.9^{\circ}$ to $6.2^{\circ}$ wider spray angle of JP- 8 under considered fuel injection pressures than that of diesel fuel [3]. This variation in the spray tip penetration and spray angle is thought to be a result of the differences in fuel properties, such as density, boiling point, and viscosity. These and other properties of fuel JP-8 contribute to higher fuel-air mixing rate and improve atomisation, resulting from shorter spray tip penetration and wider spray angle [4].

Investigating the impact of JP-8 fuel (F-34) on diesel engine performance and emission is very important for military combat vehicles, due to its great potential as alternative fuel under single fuel strategy program for military operation. Experimental studies showed that JP-8 fuels have the potential for lowering $\mathrm{NO}_{\mathrm{x}}, \mathrm{CO}, \mathrm{HC}$ emissions and smoke compared to diesel fuel. The test results of a $558 \mathrm{~kW}, \mathrm{~B}-46-6$, supercharged, 12-cylinders, CIDI engine with a hydraulic dynamometer indicate that torque and horsepower of diesel fuel can be matched with fuel economy penalty lower than $4.5 \%$, by increasing the volumetric fuel quantity to compensate the lower density of JP8 fuel. The lower cetane number of JP-8 fuel caused a slight increase in ignition delay but improved the combustion at load conditions, thus lowering the combustion noise [5].

There is a known torque and fuel economy penalty associated with the operation of a diesel engine with JP-8 fuel, due to its lower density and viscosity. On the other hand, a few experimental studies have suggested that kerosene-based fuels have the potential for lowering exhaust emissions compared to diesel fuel (DF-2). The test results obtained at the Detroit Diesel Corporation (DDC) with S60 engine outfitted with exhaust gas recirculation indicate that torque and fuel economy of diesel fuel can be matched, without smoke or $\mathrm{NO}_{\mathrm{x}}$ penalty, by increasing the duration of injection to compensate for the lower fuel density. The lower cetane number of JP-8 cause an increased ignition delay and increased premixed combustion, and their cumulative effect led to relatively unchanged combustion phasing. Under almost all conditions, JP-8 led to lower $\mathrm{NO}_{\mathrm{x}}$ and PM emissions and shifted the $\mathrm{NO}_{\mathrm{x}}-\mathrm{PM}$ trade-off favourably [6]. 


\section{Purpose of the research}

The purpose of the research is to investigate the effect of neat F-34 fuel and F-34 fuel treated with the cetane improver $(0.12 \mathrm{vol} \%$ of 2 -ethylhexyl nitrate $)$ on the combustion peculiarities, performance efficiency of direct injection diesel engine, emission composition changes, and smoke opacity of the exhausts. Objectives of the study are as follows:

1. To investigate behaviour of the autoignition delay, maximum cylinder gas pressure and the brake specific fuel consumption when operating alternately on the normal diesel fuel, jet fuel F-34 and F-34 fuel treated with $0.12 \mathrm{vol} \%$ of the cetane improver over a wide range of loads and speeds.

2. To examine the emission composition changes, such as nitrogen oxides $\mathrm{NO}, \mathrm{NO}_{2}, \mathrm{NO}_{\mathrm{x}}$, carbon monoxide $\mathrm{CO}$, total unburned hydrocarbons $\mathrm{HC}$ and smoke opacity of the exhausts when running the engine with F-34 fuel and F-34 fuel treated with $0.12 \%$ of the cetane improver over a wide range of loads and revolutions per minute.

\section{Objects, apparatus and methods of the research}

Tests have been conducted on four-stroke, four-cylinder, direct-injection, naturally aspirated 60 $\mathrm{kW}$ diesel engine D-243 with a splash volume $4.75 \mathrm{dm}^{3}$, cylinder bore $110 \mathrm{~mm}$, piston stroke $125 \mathrm{~mm}$ and compression ratio 16:1. The fuel was delivered by an in line fuel injection pump thorough five holes injection nozzles into a toroidal combustion chamber in a piston head with the stating fuel injection advance of $25^{\circ}$ before the top dead centre (TDC). The needle valve lifting pressure for all injectors was set to $17.5 \pm 0.5 \mathrm{MPa}$.

Load characteristics of the engine were taken at 1400 and $2200 \mathrm{~min}^{-1}$ speeds when operating alternately on base $95 \mathrm{vol} \%$ diesel fuel (class C) $+5 \mathrm{vol} \%$ RME (DF), neat F-34 fuel (JF) and F-34 fuel treated with the additive 2-ethylhexyl nitrate $(\mathrm{JF}+0.12 \mathrm{vol} \%)$. The additive was produced at Sigma-Aldrich Chemic Gmbh CAAS Nr. 27247-96-7 (Germany) for experiments.

Torque of the engine was measured with $110 \mathrm{~kW}$ electrical AC stand dynamometer and speed was controlled by using the universal ferrite-dynamic stand tachometer TSFU-1. The fuel mass consumption was measured by weighting it on the AVL fuel balance $(0-150 \mathrm{~kg} / \mathrm{h})$ with an accuracy of $\pm 0.12 \%$ and the air mass consumption was measured with the AVL air metering equipment installed at the air tank to reduce pressure pulsations and guarantee an accuracy of $\pm 0.25 \%$. The coolant liquid and lubricating oil temperatures were within the range of $80-85^{\circ} \mathrm{C}$.

Single and summarized over 100 engine cycles in-cylinder gas pressure diagrams versus the crank angle were recorded at every 0.1 crank angle degree (CAD) by using the AVL indication and data acquisition system. A piezoelectric un-cooled transducer GU24D (range 0-280 bar) mounted into the first cylinder and connected to the MICROIFEM piezoelectric amplifier-signal conditioning along with the AVL crank angle encoder $365 \mathrm{C}\left( \pm 0.1^{\circ}\right)$ have been used to monitor gas pressure for every load-speed setting point with an accuracy of $\geq \pm 0.1$ bar. The AVL IndiModul 622 was introduced as a multi-channel (8) indicating system for the acquisition and processing of fast crank-angle and time-based cylinder gas pressure signals. The average in-cylinder gas pressure of 100 engine cycles was used for the analysis and calculating the heat release rate.

The static fuel delivery angle of $25^{\circ}$ before the top dead centre was the same for diesel fuel and jet fuels tested under all loads and speeds. The fuel was delivered by an in-line fuel injection pump, through five holes (diameter $0.34 \mathrm{~mm}$ ) injection nozzles into a toroidal combustion chamber in a piston head. The fuel-line high-pressure was measured by using Kistler piezoresistive pressure sensors (type 4067) mounted on the injector's feeding pipe at the fuel pump and at the end of a high-pressure line with an accuracy of $\pm 0.5 \%$ within pressure range $0-100 \mathrm{MPa}$.

The dynamic start of injection and injection duration were determined by recording of the nozzle-needle-valve lifting and its history by using the Hall effects position sensor ASMB 4700041 produced at the Wolff Controls Corporation. The fuel line-pressure and needle-valve lifting signals have been transmitted to the Kistler type 4665 and 5247 amplifier modules mounted on the 
signals conditioning platform Compact $2854 \mathrm{~A}$. The data acquisition and processing system based on personal computer and equipped with a 12-bit A/D converter was used for experiments.

The autoignition delay was determined as the period in degrees $\left(\varphi_{i}\right)$ and/or units of time $\left(\tau_{i}\right)$ between the dynamic start of fuel injection and the start of combustion. As a dynamic start of injection was taken the point, at which the needle-valve lift compiles about $5 \%$ of its total $0.28 \mathrm{~mm}$ travel. As the start of combustion was taken, the point, at which the differential curve of the heat release characteristic's crosses the zero line and changes its value from minus to plus one. These critical points were determined with an accuracy \pm 0.10 of the crank angle degrees.

The amounts of nitric oxide NO (ppm), nitrogen dioxide NO2 (ppm), carbon monoxide CO (ppm) and total unburned hydrocarbons $\mathrm{HC}(\mathrm{ppm})$ in the exhausts were measured with the Testo $350 \mathrm{XL}$ gas analyser. Total emissions of nitrogen oxides NOx was determined as a sum of both $\mathrm{NO}$ and $\mathrm{NO} 2$ components.

The smoke density D (\%) of the exhausts was measured with a Bosch RTT 100/RTT 110 opacity-meter, which readings are provided as Hartridge units in a scale ranging from 0 to $100 \%$ with an accuracy of $\pm 0.1 \%$. Temperature of the exhausts was measured by using of chromel-kopel thermocouple and indicator N20 that guaranteed an accuracy of $\pm 0.2^{\circ} \mathrm{C}$.

\section{The research results and discussions}

The technical parameters of base diesel fuel, jet fuel F-34 and jet fuel F-34 treated with the cetane improver (CI) by the addition $0.12 \mathrm{vol} \%$ of 2-ethylhexyl nitrate have been evaluated at the Internationally accredited according standard EN ISO/IEC 17025-2005 Quality research centre "ORLEN Lietuva" Ltd., Mažeikiai, as shown in Tab. 1.

Tab. 1. Properties of diesel fuel (Grade C) and jet fuel (NATO Code F-34)

\begin{tabular}{|c|c|c|c|c|}
\hline Property parameters & $\begin{array}{l}\text { Test methods Diesel fuel / } \\
\text { Aviation fuel }\end{array}$ & DF EN 590 & $\begin{array}{l}\text { F-34 ASTM- } \\
\text { D } 1655\end{array}$ & $\begin{array}{l}\mathrm{F}-34+\mathrm{CI} \\
0.12 \mathrm{vol} \%\end{array}$ \\
\hline Chemical formula & & $\mathrm{C} 10-\mathrm{C} 29$ & $\mathrm{C} 8-\mathrm{C} 18$ & $\mathrm{C} 8-\mathrm{C} 18$ \\
\hline Density at $15^{\circ} \mathrm{C}, \mathrm{kg} / \mathrm{m}^{3}$ & $\begin{array}{c}\text { EN ISO 12185:1999/ } \\
\text { ASTM D 4052 } \\
\end{array}$ & 843.6 & 797.2 & 797.2 \\
\hline Kinematic viscosity at $40^{\circ} \mathrm{C}, \mathrm{mm}^{2} / \mathrm{s}$ & $\begin{array}{l}\text { EN ISO } 3104 \text { at } 40^{\circ} \mathrm{C} / \\
\text { ASTM D } 445 \text { at }-20^{\circ} \mathrm{C}\end{array}$ & 2.893 & 4.0 & 4.0 \\
\hline $\begin{array}{l}\text { Lubricity, corrected wear scar diameter } \\
\text { (wsd 1.4) at } 60^{\circ} \mathrm{C}, \mu \mathrm{m}\end{array}$ & $\begin{array}{l}\text { EN ISO 12156-1:2007 / } \\
\text { indeterminable }\end{array}$ & 460 & $\begin{array}{c}611 \\
- \\
\end{array}$ & $\begin{array}{c}729 \\
- \\
\end{array}$ \\
\hline $\begin{array}{l}\text { Flash point, Pensky-Martens closed cup, } \\
{ }^{\circ} \mathrm{C} / \text { Flash point by Tag closed cup tester }\end{array}$ & $\begin{array}{c}\text { EN ISO 2719:2003/ } \\
\text { ASTM D 56 } \\
\end{array}$ & 59.0 & 40 & 40 \\
\hline Auto-ignition temperature, ${ }^{\circ} \mathrm{C}$ & & 230 & $\approx 229$ & - \\
\hline $\begin{array}{l}\text { Cold filter plugging point ICFPP), }{ }^{\circ} \mathrm{C} / \\
\text { Freezing point, }{ }^{\circ} \mathrm{C}\end{array}$ & $\begin{array}{l}\text { EN ISO } 116 / \\
\text { AC:2002 }\end{array}$ & -7 & -58.0 & -58.0 \\
\hline Cloud point, ${ }^{\circ} \mathrm{C}$ & EN 23015 / indeterminable & -2 & - & - \\
\hline Cetane number & EN ISO 5165:1999 & 51.3 & 42.3 & 48.5 \\
\hline Sulphur, mg/kg & $\begin{array}{l}\text { EN ISO 20846:2004/ } \\
\text { ASTM D 5453-09 }\end{array}$ & 8.9 & 11 & 11 \\
\hline Acid value, $\mathrm{mg} \mathrm{KOH} / \mathrm{g}$ & $\begin{array}{c}\text { indeterminable / } \\
\text { ASTM D } 3242 \\
\end{array}$ & - & 0.001 & 0.001 \\
\hline $\begin{array}{l}\text { Carbon residue (in } 10 \% \text { distillation } \\
\text { residue), } \% \mathrm{~m} / \mathrm{m}\end{array}$ & $\begin{array}{c}\text { EN } 10370 / \\
\text { indeterminable }\end{array}$ & 0.03 & - & - \\
\hline Net heating value, $\mathrm{MJ} / \mathrm{kg}$ & $\begin{array}{c}\text { ISO 8217:2007 / } \\
\text { ASTM D 4529-01 } \\
\end{array}$ & 43.10 & 43.30 & 43.27 \\
\hline $\begin{array}{l}\text { Ash content, mass- } \% \text { / } \\
\text { Existent gum, mg/100 ml }\end{array}$ & $\begin{array}{c}\text { EN ISO 6245:2002 / } \\
\text { IP-540 } \\
\end{array}$ & 0.001 & 1 & 1 \\
\hline Water content, $\mathrm{mg} / \mathrm{kg}$ & EN ISO 12937:2002 / - & 39 & - & - \\
\hline $\begin{array}{l}\text { Total contamination, } \mathrm{mg} / \mathrm{kg}(\mathrm{ppm}) / \\
\text { Contamination, } \mathrm{mg} / \mathrm{l}\end{array}$ & $\begin{array}{l}\text { EN 12662:2008/ } \\
\text { ASTM D } 5452\end{array}$ & 2.0 & 0.2 & 0.2 \\
\hline Fraction, ${ }^{\circ} \mathrm{C}$ & - & $180-350$ & $140-230$ & $140-230$ \\
\hline
\end{tabular}


To improve lubricating properties of base jet fuel A-1 (F-35) 0.1 vol\% lubricity additive is applied. Then jet fuel is treated with anti-ice and lubricating additives to correspond NATO quality requirements for military F-34 fuel. The tested jet fuel is 5.5\% lighter than (grade C) diesel fuel $\left(846.3 \mathrm{~kg} / \mathrm{m}^{3}\right)$ and it differs as having extremely deep $-58^{\circ} \mathrm{C}$ cold filter plugging point compared to the normal diesel $\left(-7^{\circ} \mathrm{C}\right)$. Despite presence of sulphur $(11.0 \mathrm{mg} / \mathrm{kg}$, $)$ in jet fuel composition, the lower density and viscosity have tendency to decrease lubricating properties of F-34 fuel compared to commercial diesel fuel (Tab. 1). The next disadvantage is reduced cetane number 42.3 of the F-34 fuel, which is lower by $17.5 \%$ compared to commercial diesel fuel. As the test results show (Tab. 1$)$, the addition of the cetane improver $(0.12 \mathrm{vol} \%$ of 2 -ethylhexyl nitrate) into the jet fuel its cetane number increases from 42.3 to 48.5 making fuel JF $+0.12 \mathrm{vol} \%$ more suitable for using in the diesel engines. The tested jet fuel is also oxygen free and its net heating value of $43.3 \mathrm{MJ} / \mathrm{kg}$ is a little bit $(0.5 \%)$ higher compared to that $43.1 \mathrm{MJ} / \mathrm{kg}$ of diesel fuel.

On the one part, the reduced density and viscosity of jet fuel along with lower both the start of distillation curve at temperature of $145.4^{\circ} \mathrm{C}$ compared to diesel fuel $\left(177.8^{\circ} \mathrm{C}\right)$ and the vaporization end at temperature of $258.0^{\circ} \mathrm{C}$ as against that $\left(345^{\circ} \mathrm{C}\right)$ of the normal diesel may improve the evaporation characteristics and preparation of combustible mixture. The enhanced atomisation of jet fuel, reduced aromatics content (19.3\%) compared to diesel fuel $(27.5 \%)$ and lower latent heat of vaporization $(250 \mathrm{~kJ} / \mathrm{kg})$ also may contribute to faster evaporation and mixing process [3]. On the other part, the lower 42.3 cetane number of F-34 fuel compared to 51.3 of the normal diesel fuel may lead to longer autoignition delay and bigger fuel portions premixed for rapid combustion that affects the heat release rate during the first kinetic phase, increases in-cylinder gas pressures and pressure gradients.

The autoignition delay depends on the atomisation of the liquid jet fuel, vaporisation of the fuel droplets and mixing of the fuel vapours with the in-cylinder compressed hot air, as well as by the cetane number determined prehistory of combustion reactions of the fuel, cylinder compressed airand-residual gas mixture conditions, which lead to autoignition [7]. Analysis of the needle-valve lifts and in-cylinder heat release characteristics shows that the replacement of the diesel fuel by commercial aviation fuel F-34 leads to the autoignition delay longer over all loads and speeds than that of the normal diesel. Such autoignition delay behaviour matches pretty well with the test results of commercial JP-8 aviation fuel, which is comparable with military F-34 fuel, on various types of DI diesel engines obtained by other researchers $[3,5,6]$.

The fully loaded DI diesel engine powered by neat F-34 fuel exhibited the autoignition delay longer by $0.84^{\circ}(10.1 \%)$ and $1.12^{\circ}(11.0 \%)$ compared to that $8.34^{\circ}$ and $10.22^{\circ}$ measured for base diesel running at respective 1400 and $2200 \mathrm{~min}^{-1}$ speed. The addition into the F-34 fuel $0.12 \mathrm{vol} \%$ of 2-ethylhexyl nitrate improves the cetane number by $14.7 \%$ (48.5). As a result, the autoignition delay decreases over a whole load range reaching the biggest improvement of $1.29^{\circ}(15.5 \%)$ compared to that $8.34^{\circ}$ of base diesel operating under the fully opened throttle and low $1400 \mathrm{~min}^{-1}$ speed. After engine speed increases to $2200 \mathrm{~min}^{-1}$, the positive effect of the cetane improver on the autoignition delay $\varphi_{i}$ reasonably decreases due to boosted by a faster piston movement in-cylinder pressure and gas temperature. As an accumulative result of all affecting factors, the autoignition delays in CAD for diesel fuel $\left(10.22^{\circ}\right)$ and for military F-34 fuel treated with $0.12 \mathrm{vol} \%$ of the cetane improver $\left(10.25^{\circ}\right)$ coincide actually when operating under high load and high $2200 \mathrm{~min}^{-1}$ speed.

When using fuels $\mathrm{JF}$ and $\mathrm{JF}+0.12 \mathrm{vol} \%$ the maximum cylinder gas pressure is lower by $4.3 \%$ and $2.8 \%$ at $1400 \mathrm{~min}^{-1}$ speed, and $2.5 \%$ and $5.7 \%$ at rated $2200 \mathrm{~min}^{-1}$ speed compared to those $86.6 \mathrm{MPa}$ and $82.5 \mathrm{MPa}$ values of the normal diesel (Fig. 1). The influence of using neat F-34 fuel and the F-34 fuel treated with cetane improver on cylinder gas pressure gradients is negligible at low $1400 \mathrm{~min}^{-1}$ speed, however the treated jet fuel suggests pressure gradients lower for all loads at $2200 \mathrm{~min}^{-1}$ speed. Because of better atomisation and homogeneous distribution of the F-34 fuel droplets, the maximum cylinder pressure gradient decreases by $9.4 \%$ compared to that $15.9 \mathrm{bar} / \mathrm{deg}$ value of base diesel. Smother performance of the diesel engine on aviation F-34 fuel can be attributed to better air-fuel mixture prepared by a wider spray angle, shorter fuel tip penetration and improved atomisation [3]. 

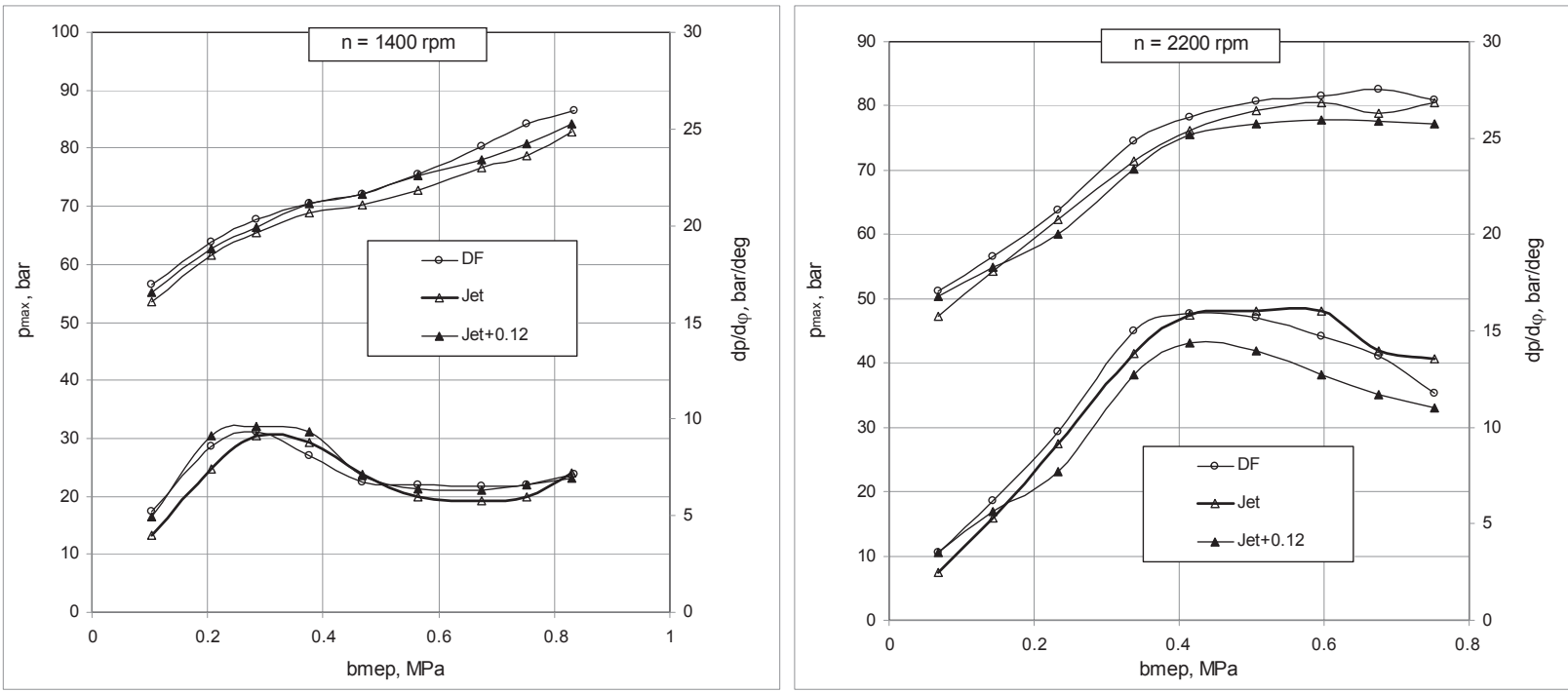

Fig. 1. The peak cylinder gas pressure $\left(p_{\max }\right)$ and pressure gradients $(d p / d \varphi)_{\max }$ as a function of engine load (bmep) at $1400 \mathrm{~min}^{-1}$ (a) and $2200 \mathrm{~min}^{-1}$ (b) speed
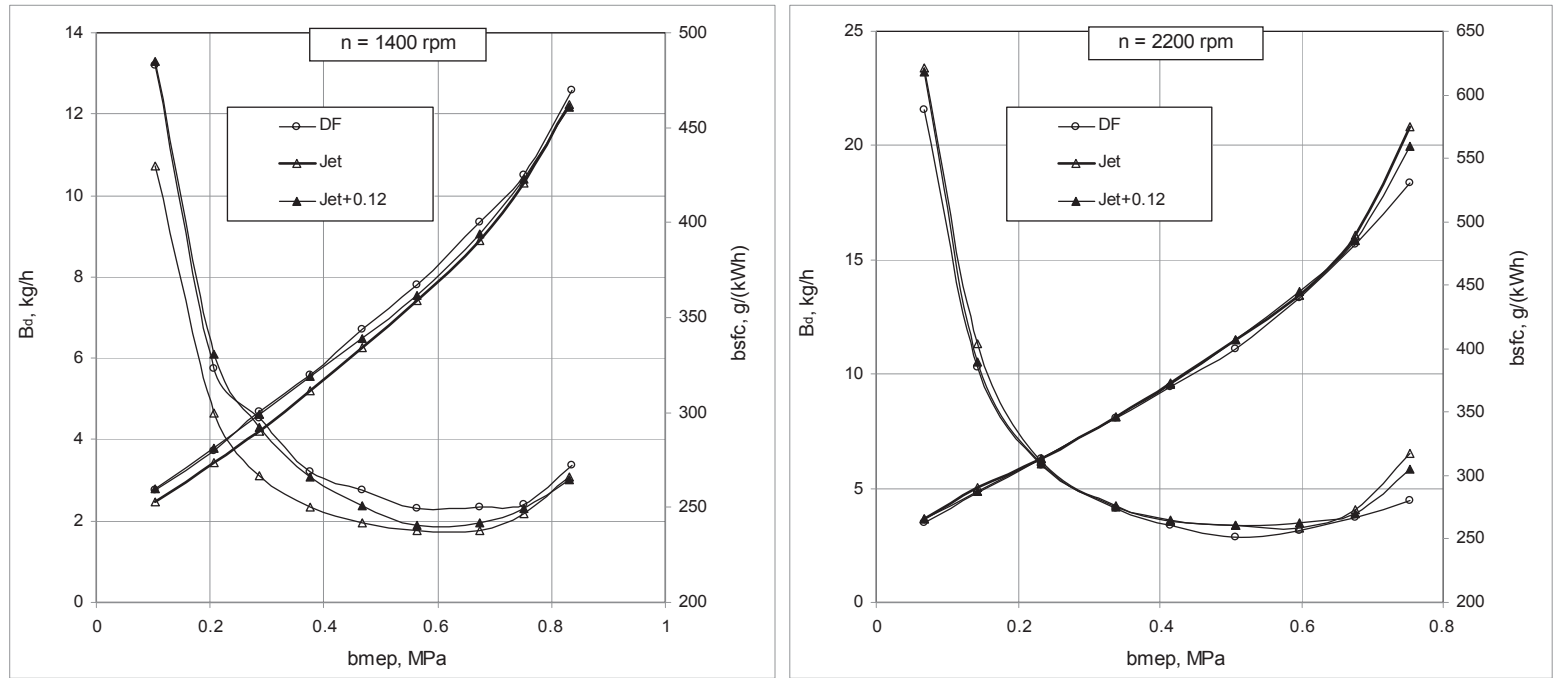

Fig. 2. The brake specific fuel consumption ( $b s f c)$ and hour fuel consumption (Bd) for DF, JF and JF+0.12vol\% as a function of engine load (bmep) at $1400 \mathrm{~min}-1$ (a) and $2200 \mathrm{~min}-1$ (b) speed

Using for diesel engine powering of aviation F-34 fuel ensures the minimum brake specific fuel consumption (bsfc) lower by $4.8 \%$ for $1400 \mathrm{~min}^{-1}$ speed and higher $2.7 \%$ for rated $2200 \mathrm{~min}^{-1}$ speed compared to respective $249.5 \mathrm{~g} / \mathrm{kWh}$ and $251.8 \mathrm{~g} / \mathrm{kWh}$ values of the normal diesel (Fig. 2). Similar the bsfc changing behaviour remains in value when engine operates on F-34 fuel treated with the cetane improver, consequently the minimum bsfc for JF $+0.12 \mathrm{vol} \%$ decreases by $3.5 \%$ and increases $3.7 \%$ at corresponding 1400 and $2200 \mathrm{~min}^{-1}$ speed.

As shows Fig. 3, when using fuel JF and fuel JF $+0.12 \mathrm{vol} \%$ the maximum nitric monoxide NO emission decreases by $11.5 \%$ and $7.0 \%$ at $1400 \mathrm{~min}^{-1}$ speed, and $17.1 \%$ and $17.3 \%$ at rated 2200 $\mathrm{min}^{-1}$ speed in comparison with respective $1705 \mathrm{ppm}$ and $1389 \mathrm{ppm}$ emanating from base diesel. Reduced NO emissions match pretty well with the lower maximum cylinder gas pressures (Fig. 1) and, hence, temperatures those play essential role in $\mathrm{NO}_{\mathrm{x}}$ production [7]. In contrast to $\mathrm{NO}$ emissions, the amounts of nitrogen dioxide $\mathrm{NO}_{2}$ did not change greatly neither with the use of F34 fuel nor with the addition of the cetane improver into F-34 fuel. As a result, the replacement of diesel fuel by F-34 fuel the total $\mathrm{NO}_{\mathrm{x}}$ emission as a sum of both $\mathrm{NO}$ and $\mathrm{NO}_{2}$ reduces drastically. 

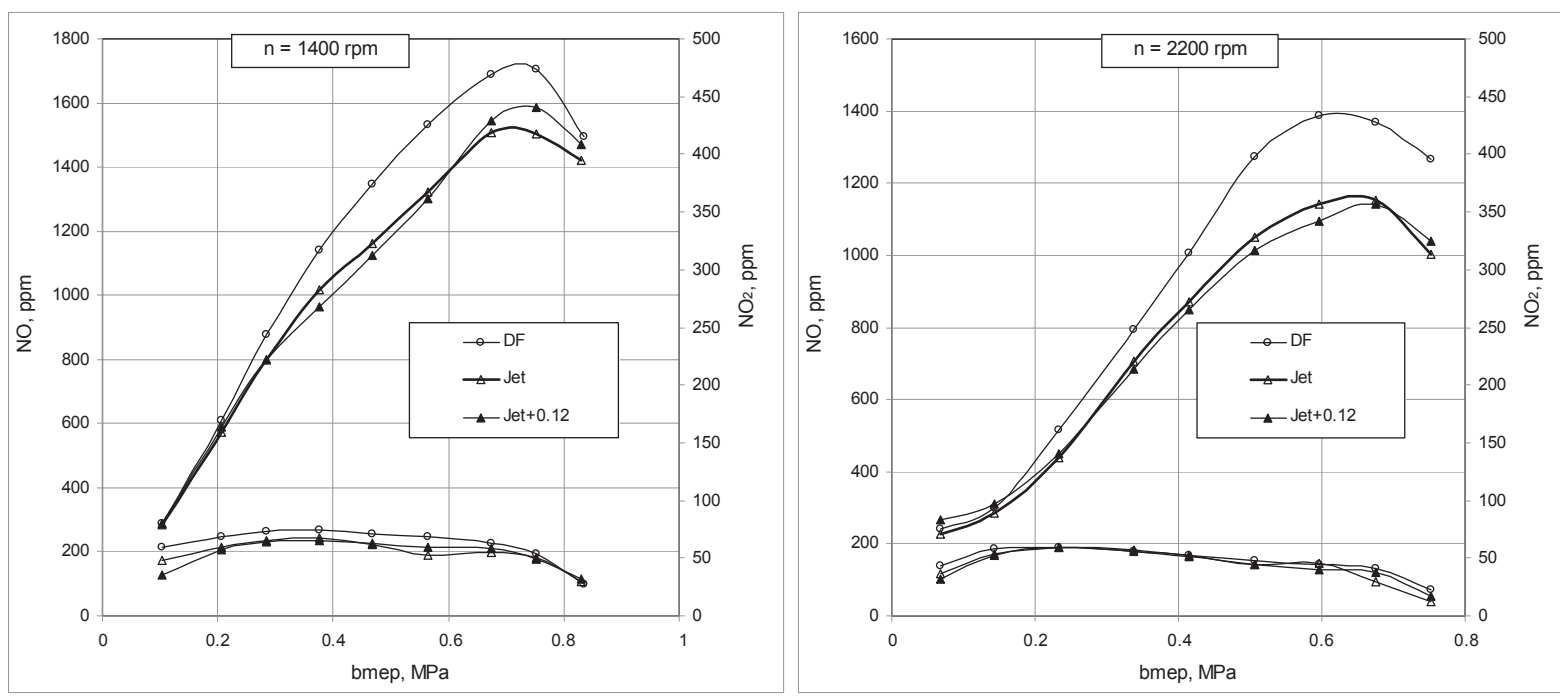

Fig. 3. The nitric monoxide $\mathrm{NO}$ and nitrogen dioxide $\mathrm{NO}_{2}$ emissions produced from $\mathrm{DF}$, JF and JF+0.12vol\% as a function of engine load (bmep) for $1400 \mathrm{~min}^{-1}$ (a) and $2200 \mathrm{~min}^{-1}$ (b) speed

The lower $\mathrm{NO}_{\mathrm{x}}$ (Fig. 3), $\mathrm{CO}$ (Fig. 4), $\mathrm{HC}$ (Fig. 5) emissions, and smoke opacity (Fig. 6) of the exhausts suggest significant environmental advantages. These benefits could be utilised by using the aviation F-34 fuel on the battlefield for land-based military aircrafts, vehicles, and equipment powered by diesel engines. Better emissions obtained in considered studies differ actually from those measured on a single-cylinder heavy duty common-rail diesel engine fuelled with JP-8, where $\mathrm{NO}$ and $\mathrm{NO}_{\mathrm{x}}$ emission were higher with both unburned carbons $\mathrm{HC}$ and carbon monoxide CO pollutants practically unaffected by the addition of every type of biodiesel in the JP-8 fuel. In that case, noted changes in harmful emissions were accompanied by slightly higher the volumetric fuel consumption under heavy loads due to addition of 50vol\% sunflower oil and/or olive oil biodiesel into aviation JP-8 fuel [2].

Replacement of traditional diesel fuel by a lighter F-34 fuel does not lead actually to big CO emissions changes when operating under low-to-medium loads and $1400 \mathrm{~min}^{-1}$ speed (Fig. 4a). The positive role of using F-34 fuel for diesel engine powering comes into effect when operating under medium-to-high loads, where maximum $\mathrm{CO}$ emissions from neat $\mathrm{JF}$ and $\mathrm{JF}+0.12 \mathrm{vol} \%$ reduce by $39.3 \%$ and $16.8 \%$ compared to $4988 \mathrm{ppm}$ produced by base diesel running at the fully opened throttle. After transition to high $2200 \mathrm{~min}^{-1}$ speed, CO emissions produced by easy and medium loaded engine increase on average from $45.9 \%$ (DF) to $103.2 \%$ (JF) compared to their $286 \mathrm{ppm}$ and $315 \mathrm{ppm}$ values measured at low $1400 \mathrm{~min}^{-1}$ speed. Because of incomplete combustion, the advantages gained by using of F-34 fuel disappear therefore $\mathrm{CO}$ emissions produced from fuels $\mathrm{JF}$ and $\mathrm{JF}+0.12 \mathrm{vol} \%$ sustain over the entire load range at more or less the same level as that of base diesel. However, when operating under heavy load and high $2200 \mathrm{~min}^{-1}$ speed, CO emissions become correspondingly by $2.5 \%$ and $3.0 \%$ higher with regard to the normal diesel.

Experimental investigation conducted in the laboratories of National Technical University of Athens and Hellenic Air Force Academy, with the main scope to evaluate the use of JP-8 aviation fuel as a full substitute for diesel fuel, revealed that JP-8 fuel combustion significantly affects some basic operating parameters of both types of engines (DI and IDI) compared to standard diesel operation. The scientists determined that the full substitution of diesel fuel with JP-8 affects positively, i.e. reduces the values of the carbon monoxide concentration while it seems to have a negligible influence on the concentration of nitrogen oxide emissions for both types engine. On the other hand, the operation of each types of engine with JP-8 fuel seems to affect seriously the values of the unburned hydrocarbons and soot emission concentrations compared to the respective values observed under normal diesel operation [8]. 

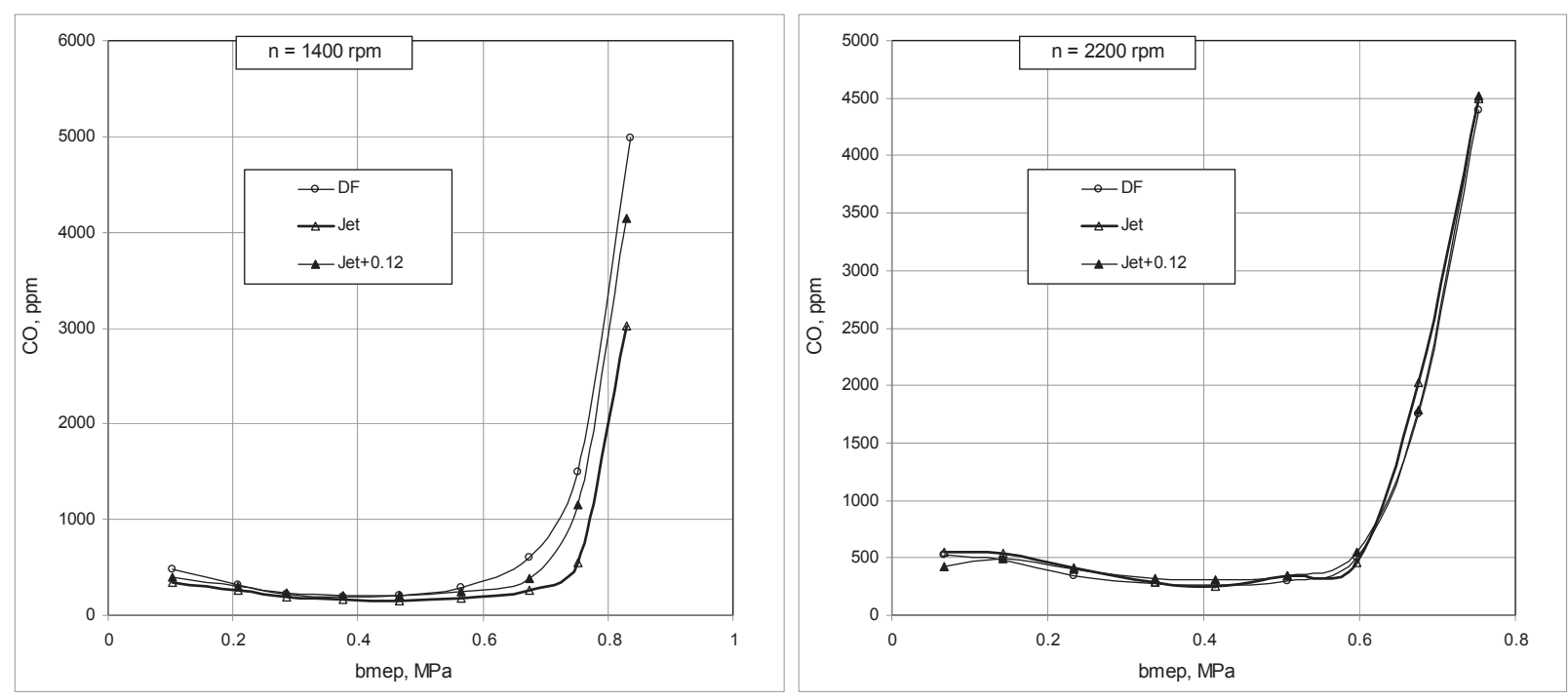

Fig. 4. Dependencies of carbon monoxide CO emissions on engine load (bmep) at $1400 \mathrm{~min}^{-1}$ (a) and $2200 \mathrm{~min}^{-1}$ (b) speed
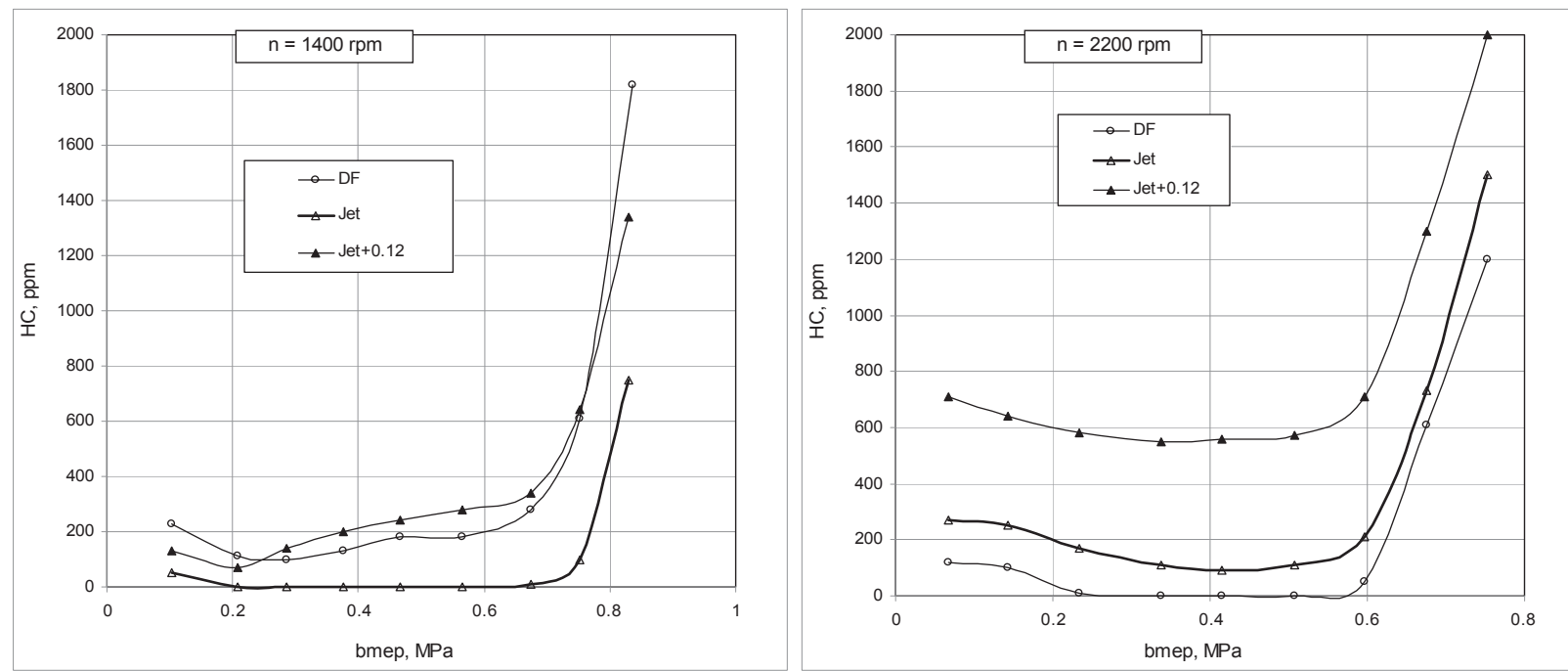

Fig. 5. Emissions of unburned hydrocarbons HC as a function of engine load (bmep) at $1400 \mathrm{~min}^{-1}$ (a) and $2200 \mathrm{~min}^{-1}$ (b) speed

Due to similar origin and nature HC pollutants change with increasing load the same way as $\mathrm{CO}$ emissions. Replacement of diesel fuel with the F-34 fuel noticeably reduces HC emissions over the all load range at $1400 \mathrm{~min}^{-1}$ speed (Fig. 5 a). When running the engine on aviation fuel under medium load at low $1400 \mathrm{~min}^{-1}$ speed, $\mathrm{HC}$ emissions reduce nearly to zero level. The HC emission produced from F-34 fuel decreases by $78.3 \%$ at low load and 58.8\% under high load compared to $230 \mathrm{ppm}$ and $1820 \mathrm{ppm}$ of base diesel. When using of treated F-34 fuel, the HC emission continues ambiguously with load, i.e. it changes from the level by $43.5 \%$ lower to $55.6 \%$ higher level compared to base diesel running under low-to-medium loads. Finally, the lower by $26.4 \%$ the HC emission with regard to base diesel fuel was achieved after transition to high load. Advantages $\mathrm{HC}$ results monitored at $1400 \mathrm{~min}^{-1}$ speed change to be more complicated after engine speed increases to $2200 \mathrm{~min}^{-1}$ mode (Fig. 5b). Emissions of hydrocarbons HC produced from both neat $\mathrm{JF}$ and treated $\mathrm{JF}+0.12 \mathrm{vol} \%$ continue at the higher levels over the whole load range. Finally, HC emissions generated from jet fuels $\mathrm{JF}$ and $\mathrm{JF}+0.12 \mathrm{vol} \%$ increase to maximum $1500 \mathrm{ppm}(25.0 \%)$ and $2000 \mathrm{ppm}(66.7 \%)$ compared to the normal diesel (1200 ppm) running under high load. 

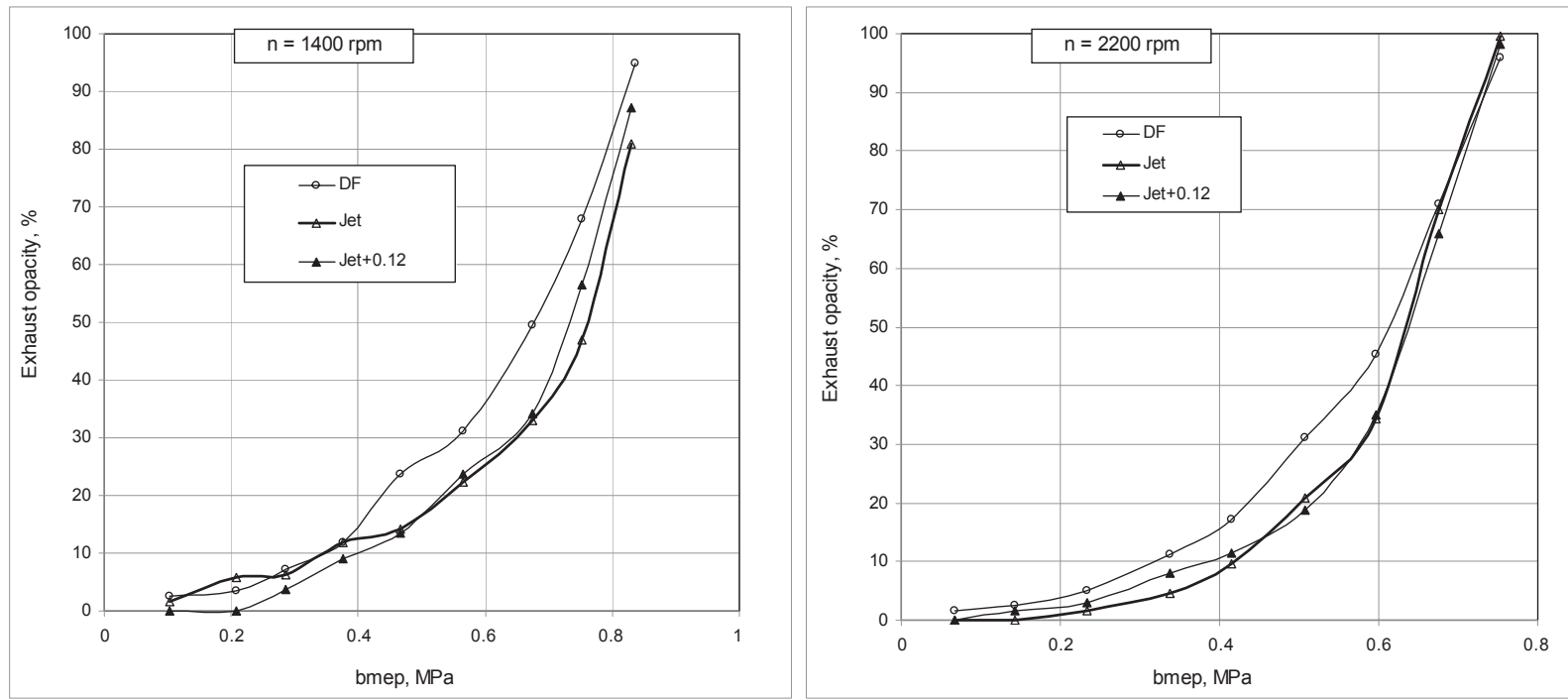

Fig. 6. Smoke opacity of the exhausts as a function of load (bmep) at $1400 \mathrm{~min}^{-1}$ (a) and $2200 \mathrm{~min}^{-1}$ (b) speed

Graphs in Fig. 6 show the smoke related advantages to be utilised by using of F-34 fuel and F34 treated with $012 \mathrm{vol} \%$ of the cetane improver in the diesel engine. By application of military aviation fuels for land-based diesel engine powering the smoke opacity could be decreased for all loads at low $1400 \mathrm{~min}^{-1}$ speed (Fig. 6 a). The smoke opacity sustains at correspondingly lower by $14.6 \%$ and $8.1 \%$ levels than that of $94.9 \%$ appearing from the normal diesel. At rated speed of $2200 \mathrm{~min}^{-1}$, the smoke opacity also decreases when using F-34 fuel and treated F-34 fuel under low-to-medium loads (Fig. 6 b). However, the positive effect of using JF and JF+0.12vol\% fuels disappears gradually with engine load, so that black smoke generated from the normal diesel, F-34 fuel and treated F-34 fuel scales up to the highest $95.8 \%, 99.6 \%$ and $98.2 \%$ levels.

\section{Conclusions}

1. The autoignition delay for F-34 fuel is $0.84^{\circ}(10.1 \%)$ and $1.12^{\circ}(11.0 \%)$ longer compared to $8.34^{\circ}$ and $10.22^{\circ}$ measured for the fully loaded diesel running at 1400 and $2200 \mathrm{~min}^{-1}$ speed. The addition into F-34 fuel $0.12 \mathrm{vol} \%$ of 2-ethylhexyl nitrate improves the cetane number (48.5) and the autoignition delay decreases by nearly $1.29^{\circ}(15.5 \%)$ over the all load range at $1400 \mathrm{~min}^{-1}$ speed. At $2200 \mathrm{~min}^{-1}$ speed, the effect of using the cetane improver decreases and the autoignition delays $10.22^{\circ}(\mathrm{DF})$ and $10.25^{\circ}(\mathrm{JF}+0.12 \mathrm{vol} \%)$ coincide actually under high load.

2. The peak in-cylinder gas pressure generated from fuels $\mathrm{JF}$ and $\mathrm{JF}+0.12 \mathrm{vol} \%$ lowers by $4.3 \%$ and $2.8 \%$ at $1400 \mathrm{~min}^{-1}$ speed, and $2.5 \%$ and $5.7 \%$ at rated $2200 \mathrm{~min}^{-1}$ speed compared to 86.6 $\mathrm{MPa}$ and $82.5 \mathrm{MPa}$ of base diesel. The treated F-34 fuel suggests cylinder pressure gradient lower for all loads at $2200 \mathrm{~min}^{-1}$ speed with its maximum value reduced by $9.4 \%$ compared to that $15.9 \mathrm{bar} / \mathrm{deg}$ of the normal diesel.

3. When running DI diesel engine on F-34, the fuel consumption per unit of energy developed depends on engine load and speed. At $1400 \mathrm{~min}^{-1}$ speed the minimum bsfc for fuel F-34 decreases by $4.8 \%$ compared to reference value of $249.5 \mathrm{~g} / \mathrm{kWh}$ whereas at rated $2200 \mathrm{~min}^{-1}$ speed the bsfc is $2.7 \%$ higher than, $251.8 \mathrm{~g} / \mathrm{kWh}$, of base diesel. The addition $0.12 \mathrm{vol} \%$ of the cetane improver 2ethylhexyl nitrate into F-34 fuel does not affect greatly the brake specific fuel consumption.

4. The biggest benefit to be utilised by application of F-34 fuel in military land-based vehicles can be attributed to significantly reduced $\mathrm{NO}$ and $\mathrm{NO}_{\mathrm{x}}$ emissions. Nitric monoxide $\mathrm{NO}$ produced from JF and JF+0.12vol\% reduces by $11.5 \%$ and $7.0 \%$ at $1400 \mathrm{~min}^{-1}$, and $17.1 \%$ and $17.3 \%$ at $2200 \mathrm{~min}^{-1}$ speed compared to $1705 \mathrm{ppm}$ and $1389 \mathrm{ppm}$ of base diesel. Maximum $\mathrm{NO}_{2}$ emissions are similar to $73.8 \mathrm{ppm}$ and $59.4 \mathrm{ppm}$ generated by base diesel at 1400 and $2200 \mathrm{~min}^{-1}$ speed. 
5. Using of jet fuel F-34 for the diesel engine powering allows keeping control also on harmful $\mathrm{CO}, \mathrm{HC}$ emissions and smoking opacity, i.e. maximum values of these pollutants could be decreased by $39.3 \%, 58.8 \%$ and $14.6 \%$ at $1400 \mathrm{~min}^{-1}$ speed. After transition to $2200 \mathrm{~min}^{-1}$ speed, the positive effect gained by using of the $\mathrm{JF}+0.12 \mathrm{vol} \%$ fuel vanishes and maximum $\mathrm{CO}$ and $\mathrm{HC}$ emissions increase by $3.0 \%$ and $66.7 \%$ compared to the normal diesel.

To support NATO Single Fuel Policy (SFP) and actualise important logistical advantages military F-34 (JP-8) fuel can be recommended for direct injection diesel engines powering in landbased military aircraft, vehicles and equipment because this kerosene based aviation fuel is economically attractive, environmental friendly and suggests smoother performance of the engine.

\section{References}

[1] Church, G. J., NATO Logistics Handbook. -SNLC Secretariat International Staff, Defence Policy and Planning Division, Logistics NATO HQ, 1110, 219 p., Brussels Belgium 1990.

[2] Arkoudeas, P., Kalligeros, S., Zannikos, F., Anastopoulos, G., Karonis, D., Korres, D., Lois, E., Study of using IP-8 aviation fuel and biodiesel in CI engines, Energy Conversion and Management, Vol. 44, Is. 7, pp. 1013-1025, 2003.

[3] Lee, J., Bae, C., Application of JP-8 in a heavy duty diesel engine, Fuel, Vol. 90, Is. 5, pp. 1762-1770, 2011.

[4] Myong, K., Suzuki, H., Senda, J., Fujimoto H. Spray inner structure of evaporating multicomponent fuel, Fuel, Vol. 87, Is. 2, pp. 202-210, 2007.

[5] Pandey, A. K., Nandgaonkar, M. R., Performance, Emission and Pump Wear Analysis of JP8 Fuel for Military Use on a $558 \mathrm{~kW}$, CIDI Diesel Engine. SAE International Technical Paper Number: 2010-01-1518. J. Fuels Lubr. 3(2):238-245, doi: 10.4271/2010-01-1518, 2007.

[6] Fernabdes, G., Fuschetto, J., Filipi, Z., Assanis, D., McKee, H., Impact of military JP-8 fuel on heavy-duty diesel engine performance and emissions, Proceedings of the Institution of Mechanical Engineers, Part D: Journal of Automobile Engineering August 1, Vol. 221, No. 8 957-970, doi: 10.1243/09544070JAUTO211, 2007.

[7] Heywood, J. B., Internal Combustion Engine Fundamentalsm - Co - Singapore for manufacture and export (International edition), 930 p., 1988.

[8] Papagiannakis, R., Kotsiopoulos, P., Hountalas, D., Yfantis, E., Single Fuel Research Program Comparative Results of the Use of JP-8 Aviation Fuel versus Diesel Fuel on a Direct Injection and Indirect Injection Diesel Engine, SAE International Technical Paper Number: 2006-011673, doi: 10.4271/2006-01-1673, 2006. 